\title{
Predictors of Unfavourable Seizure Outcome in Patients with Epilepsy in Nepal
}

\author{
Subash Lohani, Upendra P. Devkota, Hemav Rajbhandari
}

\begin{abstract}
Background: Despite optimal medical therapy, a sizeable number of patients continue to have persistent seizures. We evaluated the association of pretreatment and treatment variables with unfavorable seizure outcome. Methods: Patients with follow-up over 12 years in the Nepal Epilepsy Association were evaluated. Patients having seizures for at least a year and already on polytherapy after failure of two monotherapy trials were considered having unfavourable outcome. Variables under study were: age, sex, duration and frequency of seizures prior to treatment, type of seizure, neurological status, Computed Tomography (CT) finding, and failure of first anti-epileptic drug (AED). Bivariate analysis was done with Chi-square and Fisher exact tests. Potential interaction between variables was studied with a logistic regression analysis. Results: Out of a total 529 consecutive patients, 490 were included in the study. Unfavorable seizure outcome was seen in $26.8 \%$ of patients. Among 284 patients who remained viable for analysis, bivariate analysis showed significant association of unfavorable outcome with frequency of seizure ( $\mathrm{p} 0.01$ ), abnormal neurological status ( $\mathrm{p} 0.01)$ and failure of first AED ( $\mathrm{p} 0.00$ ), while no significant association was seen with age at onset ( $\mathrm{p} 0.45)$, sex (p 0.47), duration of seizure (p 0.43 ), type of seizure ( $\mathrm{p} 0.12$ ), and presence of CT abnormality ( $\mathrm{p} 0.46$ ). The fitted regression model portended an unfavorable prognosis with failure of first AED and abnormal neurological status, however, failed to show significant association with frequency of seizure. Conclusions: Failure of first AED trial and associated neurological deficits are significant predictors of unfavorable seizure outcome.
\end{abstract}

RÉSUMÉ: Facteurs de prédiction d'une issue défavorable des crises chez les patients atteints d'épilepsie au Népal. Contexte : Un nombre appréciable de patients continue à présenter des crises malgré un traitement médical optimal. Nous avons évalué l'association entre certaines variables avant et après traitement chez les patients dont les crises n'étaient pas bien contrôlées. Méthodes : Nous avons évalué les patients de la Nepal Epilepsy Association qui étaient suivis depuis plus de 12 ans. Les patients qui avaient des crises depuis au moins un an et qui étaient déjà sous polythérapie suite à un échec d'au moins deux essais de monothérapie ont été considérés comme ayant un mauvais résultat. Nous avons étudié les variables suivantes : l'âge, le sexe, la durée et la fréquence des crises avant traitement, le type de crises, l'état neurologique, les constatations à la tomodensitométrie et l'échec du traitement par le premier médicament antiépileptique (MAE). Une analyse bivariée a été effectuée au moyen du chi-carré et du test de Fisher, et l'interaction entre les variables a été évaluée au moyen de l'analyse de régression logistique. Résultats : Quatre cent quatre-vingt-dix des 529 patients consécutifs ont été inclus dans l'étude. Une issue défavorable a été observée chez 26,8\% des patients. Parmi les 284 patients analysables, l'analyse bivariée a montré une association significative entre une issue défavorable et la fréquence des crises $(\mathrm{p}=0,01)$, un état neurologique anormal $(\mathrm{p}=0,01)$ et un échec du premier MAE $(p=0,00)$. Aucune association significative n'a été observée avec l'âge de début $(p=0,45)$, le sexe $(p=0,47)$, la durée des crises $(\mathrm{p}=0,43)$, le type de crises $(\mathrm{p}=0,12)$ et la présence d'anomalies à la tomodensitométrie $(\mathrm{p}=0,46)$. Le modèle de régression ajusté qui prédisait un pronostic défavorable en présence d'un échec du premier MAE et d'un état neurologique anormal ne montrait cependant pas d'association significative avec la fréquence des crises. Conclusions : L'échec du traitement par le premier MAE et la présence de déficits neurologiques sont des facteurs qui prédisent une mauvaise réponde au traitement.

Can. J. Neurol. Sci. 2010; 37: 76-80

Epilepsy is a common neurological ailment in Nepal. A community based survey ${ }^{1}$ done in the Morang district of Nepal had shown the prevalence to be 7.3 per 1000 population, which is in accordance with that in other studies. ${ }^{2,3}$

Despite optimal medical therapy, up to $30 \%$ of patients tend to develop intractable epilepsy. ${ }^{4}$ Several prognostic factors have been identified for therapy refractoriness, such as: age of onset, type of seizure, number, frequency, and duration of seizures prior to initiation of treatment, status epilepticus, postnatally acquired brain lesions, neurological deficits, electoencephalogram (EEG) abnormalities, and failure of first anti-epileptic drug (AED). ${ }^{5-16}$
This study was conducted among patients with epilepsy in Nepal who were given a diagnosis, treated and followed up in a single center. Various pretreatment and treatment variables that

From the National Institute of Neurological and Allied Sciences (SL, UPD); Nepal Epilepsy Association (HR), Lazimpat, Kathmandu, Nepal.

Received March 30, 2009. Final Revisions Submitted August 10, 2009. Correspondence to: Subash Lohani, National Institute of Neurological and Allied Sciences, Bansbari, Kathmandu, Nepal. 
have been identified by previous studies to be associated with intractability were analyzed to ascertain the predictors of unfavorable seizure outcome in pertinence to the characteristics of this particular cohort.

\section{Patients And Methods}

This is a retrospective study conducted among patients with epilepsy under regular follow-up at a single institution. This institution, located in the capital city Kathmandu, has a broad catchment area. Until recently, it provided anti-epileptic medications free-of-cost on Korean Aid. A total of 529 consecutive patients received treatment from Nepal Epilepsy Association between March 1995 and December 2007. Patients who had no follow-up at all and those whose cases files were inadequately maintained were excluded from the study.

Treatment approach: Patients were regularly called for follow-up every three to six months. Clinical information, intolerance of drugs and compliance were noted at each visit. Initially patients were treated with a single drug. Drug doses were based on clinical circumstances. If patients had persistent seizures despite medication, had intolerable side effects or developed idiosyncratic reactions, second AED was started, which was a monotherapy in most instances and occasionally polytherapy as per the judgement of the treating doctor. Subsequently, other combination of drugs was used when the seizures were still not controlled. On identification of surgically amenable lesions, patients were considered for neurosurgical referral. Neuroimaging had not been routinely performed in the past because of unavailability of imaging facilities and cost to patients.

Variables for the predictors of refractory epilepsy were selected based on previously published articles. Thorough electronic search of related articles using the search engine Google, Pubmed and Medline was performed for 'predictors', 'refractory' and 'epilepsy'. A proforma was developed based on all predictor variables. Thorough review of each case profile was done to record them, including information on treatment trials, follow-up, and status of seizure control.

Definition: Seizure types were classified based on the International League Against Epilepsy seizure classification. ${ }^{17,18}$ Categorization of each case into particular type was at the discretion of the treating physician based on history, clinical findings and supportive investigations. Seizure control was assessed based on the most recent seizure status recorded. Patient was considered to be 'seizure free' when no seizures occurred for at least the preceding six months, as response to AED at six months has been shown to be an excellent predictor of so at 12 months. ${ }^{12}$ 'Seizures despite medication' category was assigned for those with at least six months of treatment, yet experiencing seizures, irrespective of frequency. 'Remission' was defined as seizure free period of at least five years..$^{5}$ 'Relapse' was defined as occurrence of one or more seizures after a patient had been withdrawn from medications. Patients who had less than six months follow-up or were known to be non-compliant were considered to have 'unevaluable seizures'. Failure of AED was not considered when the switch of drug was made due to adverse reactions or intolerance of side effects. Seizure prognosis was broadly categorized as 'favorable' (seizure free, remission) and 'unfavorable' (seizures for at least a year and already on polytherapy after failure of two monotherapy trials) for analysis consideration. As the patients with 'relapse' are in fact the ones who have seizures that are well controlled with medications, they were also considered as favorable category as far the prediction is concerned.

Neurological examination was considered abnormal only when definite abnormalities were present in cranial nerves, motor, sensory, cerebellar, reflexes, plantars and fundus, including cognitive impairment, developmental delay or mental retardation. Mere radiological findings in isolation or presence of risk factors like history of head injury, meningoencephalitis or cerebrovascular accident (CVA) in presence of normal neurological examination was not considered for categorization as 'neurological deficit'. 9

Statistical Analysis: Various pretreatment and treatment variables were analyzed to ascertain the variability on seizure outcome; categorized as favorable and unfavorable. Variables under study were: age, sex, duration of seizures prior to treatment, frequency of seizures prior to treatment, type of seizure, neurological deficit, Computed Tomography (CT) findings and failure of first AED. Age, duration and frequency were splited into subgroups for statistical analysis. Bivariate analysis was done with Pearson Chi-square test and Fisher exact test for comparisons of categorical data (binomial and multinomial). Potential interaction between the variables was studied in a multivariate analysis by logistic regression model. Odds ratio with $95 \%$ confidence interval was calculated using logistic regression model with an assumption based on normal approximation. All statistical tests were two-tailed. $\mathrm{P}$ value $<0.05$ was considered statistically significant. SPSS v 11.5.0 was used for statistical analysis.

\section{RESUlts}

Out of 529 consecutive patients, 490 were included in the study. Thirty-nine patients did not return for follow-up. There were 310 males $(63.3 \%)$ and 180 females $(36.7 \%)$. Mean age of patients was 23.63 years (SD 11.61, 2-68).

Age, duration and frequency: Fourteen patients (2.9\%) had seizure onset before the age of one year, while $32 \%$ had that at or beyond the age of $20 \mathrm{yrs}$. There were $18.5 \%$ and $46.5 \%$ of patients in 1-9 and 10-19 yrs age group respectively. At first presentation, $50 \%$ had untreated seizures for more than one year and only $6.5 \%$ presented with seizures of less than a month duration. Among the patients with more than a year of seizure at first presentation, mean seizure duration prior to treatment initiation was 77.9 months (SD 64.02). Pretreatment seizure frequency of two or more was present in $46.1 \%$, while $26.9 \%$ had seizures less than once a month and $16.5 \%$ had them once a month.

Type of seizure: Generalized seizures were present in $73.3 \%$ of the patients, while $24.1 \%$ were partial ones. Four patients had mixed generalized and partial seizures. Among the generalized seizures, $97.8 \%$ were recorded as tonic, clonic or tonic-clonic. Three patients were documented to have absence seizures and two as atonic seizures. Among the partial ones, $65 \%$ were simple partial, while $25.9 \%$ were complex partial seizures.

Neurology, Imaging and EEG: Twenty-four patients (4.9\%) had family history of epilepsy. Eleven patients $(2.2 \%)$ had history of febrile seizures. Thirteen patients had history of 
significant head injury while 18 had an episode of meningoencephalits prior to the onset of seizures. Thirty-eight patients $(7.8 \%)$ had abnormal findings on neurological examination. There were 18 patients $(3.67 \%)$ with cerebral palsy, while only two with CVA. A CT scan was performed in 175 patients. Normal scan was noted in $65.98 \%$, while $27.21 \%$ had focal abnormalities, $2.72 \%$ had diffuse abnormalities and $4.08 \%$ had multifocal abnormalities. Focal granulomatous lesion consistent with neurocysticercosis was seen in $46 \%$ of abnormal scans. Other neurological abnormalities identified on CT and magnetic resonance imaging were gliomas, venous angioma, Fahr's disease, polymicrogyria, etc.

Electroencephalogram was performed in 188 patients. Normal EEG was seen in $33.5 \%$, while $20.8 \%$ had focal epileptiform abnormalities, and $12 \%$ had generalized epileptiform abnormality. Yet another $33.5 \%$ had epileptiform abnormality otherwise not specified.

Seizure status and treatment trial: With exclusion of unevaluable seizures, $47.64 \%$ of patients were seizure free, $8.8 \%$ went on remission, $4.7 \%$ had relapse, while $38.8 \%$ were having seizures despite medications. Mean duration of treatment despite seizures not being controlled with medications was 46.51 months (SD 37.57, min 4 and $\max 168$ ). Irrespective of seizure status, $60.2 \%$ patients were on first AED trial while, $6.3 \%$ were on second monotherapy, and $33.5 \%$ were either on second poly- therapy or subsequent therapeutic trials. Out of 284 patients who remained viable for the analysis of prediction, $26.8 \%$ had unfavourable seizure outcome.

Results of statistical analysis: Regarding the prognosis of seizure, with bivariate analysis of eight different variables (Table 1 ), significant association was seen with the frequency of seizure prior to treatment ( $\mathrm{p}$ value 0.01 ), abnormality in neurological examination ( $\mathrm{p}$ value 0.01 ), and failure of first AED ( $\mathrm{p}$ value 0.00 ), while no significant association was seen with the age at onset ( $p$ value 0.45 ), sex ( $p$ value 0.47 ), duration of seizure prior to treatment ( $\mathrm{p}$ value 0.43 ), type of seizure ( $\mathrm{p}$ value 0.12 ), and presence of CT abnormality (p value 0.46 ). Regarding duration of seizures, even when treatment was delayed beyond 48 months, there was no significant association with unfavorable outcome ( $p$ value 0.42 ). Seizure onset below age of one year ( $p$ value 0.11 ) and those beyond 20 yrs ( $p$ value 0.58 ) did not have any significant association with unfavorable outcome.

In bivariate analysis, while we found three variables significantly associated with unfavourable seizure outcome, in multivariable analysis, only two variables were significant (Table 2). The risk of unfavourable seizure was nearly seven times higher in patients with neurological deficit. This risk was even higher in the patients with failure of first AED than those who responded to initial treatment.

Table 1: Categorical variables and seizure outcome; results of bivariate analysis (Two-tailed Pearson Chi-Square test and Fisher Exact test) $\quad N:=90-284$

\begin{tabular}{|c|c|c|c|c|c|}
\hline \multirow[t]{2}{*}{ Variable } & \multirow[t]{2}{*}{ Category } & \multirow[t]{2}{*}{ Frequency (no. cases) } & \multicolumn{2}{|c|}{ Seizure outcome } & \multirow[t]{2}{*}{$P$ value } \\
\hline & & & Favorable & Unfavorable & \\
\hline \multirow[t]{2}{*}{ Seizure type } & Partial & 63 & 40 & 21 & 0.12 \\
\hline & Generalized & 213 & 161 & 52 & \\
\hline \multirow[t]{2}{*}{ Neurological deficits } & Present & 16 & 7 & 9 & $0.01 *$ \\
\hline & Absent & 268 & 201 & 67 & \\
\hline \multirow[t]{3}{*}{ Duration } & $>12 \mathrm{mth}$ & 129 & 98 & 31 & 0.43 \\
\hline & $1-12 \mathrm{mth}$ & 56 & 46 & 10 & \\
\hline & $<1 \mathrm{mth}$ & 19 & 13 & 6 & \\
\hline \multirow[t]{4}{*}{ Frequency } & $>2 / \mathrm{mth}$ & 92 & 57 & 35 & $0.01 *$ \\
\hline & $2 / \mathrm{mth}$ & 18 & 11 & 7 & \\
\hline & $1 / \mathrm{mth}$ & 47 & 35 & 12 & \\
\hline & $<1 / \mathrm{mth}$ & 86 & 71 & 15 & \\
\hline \multirow[t]{2}{*}{ AED trial } & Second or above & 150 & 76 & 74 & $0.00 *$ \\
\hline & First & 134 & 132 & 2 & \\
\hline \multirow[t]{5}{*}{ Age of onset } & $>20$ yrs & 95 & 72 & 23 & 0.45 \\
\hline & $10-19$ yrs & 127 & 95 & 32 & \\
\hline & $5-9$ yrs & 26 & 19 & 7 & \\
\hline & $1-4$ yrs & 18 & 12 & 6 & \\
\hline & $<1 \mathrm{yrs}$ & 5 & 2 & 3 & \\
\hline \multirow[t]{2}{*}{ Sex } & Male & 178 & 133 & 45 & 0.47 \\
\hline & Female & 106 & 75 & 31 & \\
\hline \multirow[t]{2}{*}{$\mathrm{CT}$} & Abnormal & 33 & 25 & 8 & 0.46 \\
\hline & Normal & 57 & 39 & 18 & \\
\hline
\end{tabular}

! N' variable owing to some missing values; * Statistically significant 
Table 2: Output of the fitted logistic regression models with unfavorable prognosis being the dependent variable $\mathrm{N}=284$

\begin{tabular}{l|l|l|l|l|l}
\hline \multirow{2}{*}{$\begin{array}{l}\text { Seizure } \\
\text { outcome (a) }\end{array}$} & & P value & OR & \multicolumn{2}{|c}{$95 \%$ CI for OR } \\
\hline & & & & LB & UB \\
\hline Unfavourable & Intercept & .00 & & & \\
\cline { 3 - 7 } & Neurological deficit & .02 & 6.69 & 1.37 & 32.67 \\
\cline { 3 - 7 } & Failure of first AED & .00 & 71.82 & 16.51 & 312.44 \\
\cline { 3 - 7 } & &
\end{tabular}

OR, odds ratio; CI, confidence interval; LB, lower bound; UB, upper bound. (a) The reference category is: Favourable outcome.

\section{DISCUSSION}

Consistent with other studies, $26.8 \%$ of the patients in this series had unfavorable seizure outcome. ${ }^{4,15}$ Several factors that suggest proclivity to intractability have already been identified. Undue prolongation of medical therapy despite poor seizure control cannot be justified, especially when viable surgical options have already been established. ${ }^{19,20}$ Yet, patients had been treated for a mean duration of 46.51 months despite having uncontrolled seizures while on medication.

Since patients in this part of world still entertain traditional health practices, it is not uncommon for an epileptic patient to have delayed presentation. At first presentation, $50 \%$ of the patients in this series had untreated seizures for more than one year with mean duration of delayed presentation among them being 77.9 months. Yet no significant association was seen with unfavorable outcome even if the first presentation was delayed beyond two years. Long duration of seizure prior to treatment initiation has been described to portend unfavorable outcome..$^{21}$ Yet in others it did not appear to contribute significantly to the outcome..$^{9,15}$

Association of high initial seizure frequency and unfavorable seizure outcome has previously been demonstrated.${ }^{15}$ Number of seizures prior to treatment initiation is merely a function of frequency and duration of seizure prior to treatment. It has also been shown to be associated with unfavorable outcome. ${ }^{7,10}$ This can probably be attributed to the phenomenon of kindling, whereby high number of pretreatment seizures consequently leads to intractability. ${ }^{22}$ This series neither showed significant association with duration and frequency of seizure nor with number of seizures prior to the initiation of treatment. In one other study too, absolute number of seizures has been demonstrated not to be significantly associated with outcome. ${ }^{6}$

Failure of first AED is a strong marker of refractoriness ${ }^{8,10,15}$ and the response to AED at six months is an excellent predictor of that at 12 months. ${ }^{12}$ In this series too, once the patient had been on second AED trial, there was a significant association with unfavorable outcome.

Prognosis for remission of epilepsy is poor in patients with associated neurologic dysfunction., ${ }^{5,14}$ This series shows significant association of neurological deficits with unfavorable outcome. Most of these patients were attributed to cerebral palsy, a common neurological entity know to cause medically intractable seizures. ${ }^{23}$ Mere finding of a neuroimaging abnormality was not shown to have a significant association. This could be related to large number of cases attributable to neurocysticercosis. It is one of the most common identifiable patho-entity related to epilepsy in our setting, ${ }^{1}$ including present series. Though the outcome of neurocysticercosis has not been separately analysed in current series, previous studies have remarkably shown its benign nature. Neurocysticercosis has been shown to have one of the best results with AEDs even without cysticidal drugs. In more than $60 \%$ of the cases in a study by Gupta et al, both the groups with and without AEDs resulted in disappearance of lesion and more than $85 \%$ of cases had no recurrence after stopping AED. ${ }^{24}$ In a follow-up of patients with single CT enhancing lesion by Murthy and Subba, $63 \%$ cases just had one episode of seizure and only $37 \%$ cases had recurrence of seizures. ${ }^{25}$ Most of the cases of recurrence were attributed to persistence of calcified lesion. ${ }^{24-26}$

Childhood onset epilepsy has its separate identity among the epileptic family. Previous studies have shown association of intractability not only with onset below one years of age but throughout the age range, with increasing age at onset having a better prognosis, within the pediatric population. ${ }^{27}$ At the other extreme, onset after 20 years too has been associated with unfavorable prognosis. ${ }^{5}$ However, this series fails to show any such association of age and unfavorable outcome; not even among those with onset below one year-of-age or beyond 20 years. Unfavorable outcome in late onset epilepsy is due to their increased likelihood of having focal etiology, of which neurocysticercosis is the most common in our series. Localization related epilepsies are less likely to be controlled than idiopathic generalized epilepsies,,$^{10,13}$ especially those with non-idiopathic localization-related syndromes. ${ }^{6}$ No significant association of seizure type and outcome was seen in the present series.

Nearly one-fourth of patients with epilepsy have unfavorable seizure outcome. Identification of risk factors are the pointers that some epilepsies are preordained to be refractory. Early identification of such patients allows window for early surgical evaluation and spares the patients from undue prolonged efforts of seizure control using AEDs. Failure of first AED and presence of neurological deficits were identified as significant predictors of unfavorable outcome. Epilepsy commencing in adulthood, localization related seizures, prolonged pretreatment seizures or mere finding of a neuroimaging abnormality may not necessarily have a bad prognosis. Depending upon the etiology, neurocysticercosis for instance, favorable outcome can still be expected. Though the results have been based on a large cohort, a pressing need of further studies to substantiate these findings need not be underscored.

\section{REFERENCES}

1. Rajbhandari KC. Epilepsy in Nepal. Can J Neurol Sci. 2004;31(2): 257-60.

2. Hauser WA, Annegers JF, Kurland LT. Incidence of epilepsy and unprovoked seizure in Roshester Minnesota 1935-1984. Epilepsia. 1993;34(3):453-68. 
3. Placencia M, Shorvon SD, Paredes V, Bimos C, Sander JW, Suarez $\mathrm{J}$, et al. Epileptic seizures in the Andean region of Ecuador. Incidence and prevalence and regional variation. Brain. 1992;115(Pt 3):771-82.

4. Sander JW. Some aspects of prognosis in the epilepsies: a review. Epilepsia. 1993;34(6):1007-16.

5. Annegers JF, Hauser WA, Elveback LR. Remission of seizures and relapse in patients with epilepsy. Epilepsia. 1979;20(6):729-37.

6. Berg AT, Shinnar S, Levy SR, Testa FM, Smith-Rapaport S, Beckerman B. Early development of intractable epilepsy in children. Neurology. 2001;56(11):1445-52.

7. Camfield C, Camfield P, Gordon K, Dooley J. Does the number of seizures before treatment influence ease of control or remission of childhood epilepsy? Not if the number is 10 or less. Neurology. 1996;46(1):41-4.

8. Camfield PR, Camfield CS, Gordon K, Dooley JM. If a first antiepileptic drug fails to control a child's epilepsy, what are the chances of success with the next drug? J Pediatr. 1997;131 (6):821-4

9. Collaborative Group for the Study of Epilepsy. Prognosis of epilepsy in newly referred patients: a multicenter prospective study of the effects of monotherapy on the long-term course of epilepsy. Epilepsia. 1992;33(1):45-51.

10. Kwan P, Brodie MJ. Early identification of refractory epilepsy. N Engl J Med. 2000;342(5):314-9.

11. Mattson RH, Cramer JA, Collins JF. Prognosis for total control of complex partial and secondarily generalized tonic clonic seizures. Department of Veterans Affairs Epilepsy Cooperative Studies No. 118 and No. 264 Group. Neurology. 1996;47(1): 68-76.

12. Schmidt D. How reliable is early treatment response in predicting long term seizure outcome. Epilepsy Behav. 2007;10(4):588-94.

13. Semah F, Picot MC, Adam C, Broglin D, Arzimanoglou A, Bazin B, et al. Is the underlying cause of epilepsy a major prognostic factor for recurrence? Neurology. 1998;51(5):1256-62.

14. Shinnar S, Berg AT. Does antiepileptic drug therapy prevent the development of chronic epilepsy? Epilepsia. 1996;37(8):701-8.

15. Sillanpää M. Remission of seizures and predictors of intractability in long-term follow-up. Epilepsia. 1993;34(5):930-6.
16. Sillanpää M, Jalava M, Kaleva O, Shinnar S. Long-term prognosis of seizures with onset in childhood. $N$ Engl J Med. 1998;338(24):1715-22.

17. Commission on Classification and Terminology of the International League Against Epilepsy. Proposal for revised clinical and electroencephalographic classification of epileptic seizures. Epilepsia. 1981;22:489-501.

18. Commission on Classification and Terminology of the International League Against Epilepsy. Proposal for revised classification of epilepsies and epileptic syndromes. Epilepsia. 1989;30(4): 389-99.

19. Rapport RL 2nd, Ojemann GA, Wyler AR, Ward AA Jr. Surgical management of epilepsy. West J Med. 1977;127(3):185-9.

20. Langfitt JT, Wiebe S. Early surgical treatment for epilepsy. Curr Opin Neurol. 2008;21(2):179-83.

21. Schmidt D, Richter K. Alternative single anticonvulsant drug therapy for refractory epilepsy. Ann Neurol. 1986;19(1):85-7.

22. Reynolds EH. Do anticonvulsants alter the natural course of epilepsy? Treatment should be started as early as possible. BMJ. 1995;310(6973): 176-7.

23. Girija AS. Medical management of intractable epilepsy. Calicut Med J. 2004; 2(4):e6; doi: Available from: http://www.calicut medicaljournal.org/2004/2/4/e6.

24. Gupta M, Agarwal P, Khwaja GA, Chowdhury D, Sharma B, Bansal $\mathrm{J}$, et al. Randomized prospective study of outcome of short term antiepileptic treatment in small single enhancing CT lesion in brain. Neurol India. 2002;50(2):145-7.

25. Murthy JM, Subba Reddy YV. Prognosis of epilepsy associated with single CT enhancing lesion: a long term follow up study. J Neurol Sci. 1998;159:151-5.

26. Garg RK, Nag D. Single enhancing CT lesion in Indian patients with seizures : clinical and radiological evaluation and follow up. J Trop Pediatrics. 1999;44:204-10.

27. Berg AT, Levy SR, Novotny EJ, Shinnar S. Predictors of intractable epilepsy in childhood. A case control study. Epilepsia. 1996;37(1):24-30. 